\title{
Analysis on the Training Strategy of Critical Thinking Ability under the Perspective of "Internet + " College English Intercultural Communication
}

\author{
Deping Zou \\ School of foreign languages, Qilu normal university, Jinan, Shandong, 250000, China
}

Keywords: Internet+; speculative ability training; intercultural communication; new approach

\begin{abstract}
In the era of "Internet +", almost anything can catch the high-speed train on the Internet. With the rapid development of the Internet, everything is changing rapidly. With the help of "Internet +", compared with traditional teaching, the current mode of thinking ability training is undergoing rapid changes. Although with the help of mutual "networking +", new teaching forms such as micro-teaching, MOOC teaching, and flipping classroom teaching have emerged in the cultivation of speculative ability, and have been recognized by students, and have received good results, but due to various kinds of reason, the introduction and practical application of students' cross-cultural thinking ability training in the cultivation of critical thinking ability is still lagging behind.
\end{abstract}

\section{Introduction}

With the help of "Internet +", how to explore new students' cross-cultural thinking ability is a question that every English teacher should seriously think about and try. Based on the actual teaching situation, the author expounds a new way to cultivate students' cross-cultural thinking ability in the cultivation of speculative ability under the "Internet +" situation.

\section{The status quo of students' cross-cultural thinking ability}

At present, most of the thinking ability training of Chinese universities is still based on linguistic knowledge such as vocabulary, grammar and writing, and cultural content is rarely explained. Most of the cultural content that teachers have in the textbooks is just passing by, and some even ignore them. For a considerable number of teachers, the ability to develop thinking in the UK is either for the students to pass the final exam or for the students to pass the 4th and 6th exams. There are still some teachers whose own cultural teaching knowledge is not enough, and their cross-cultural thinking ability and literacy still need to be further improved, which is one of the reasons for teachers to emphasize linguistic culture. At present, the cultivation of speculative ability in Chinese universities is basically taught by teachers in the cultural part of the textbook. Students are also free to learn according to their own interests. Teachers' teaching methods such as linguistic and light culture make students mistakenly believe that cultural learning is dispensable. Although students have been studying English for several years, they still know very little about culture. Due to the 
lack of cultural knowledge, they often have various obstacles in intercultural communication. For example, in the process of using English communication, there are often misuses and even misunderstandings [1].

\section{The necessity of cultivating students' cross-cultural thinking ability}

After the reform and opening up, China's economy has developed rapidly, and cross-cultural and cross-cultural exchanges have become increasingly frequent. However, due to differences in geographical location, natural environment, ethnic origin, historical changes, religious beliefs, and economic development levels, China and the West have great differences in values, social norms, and cultural norms. These differences have led to great differences in cultural practices between China and the West. This customary difference will lead to cultural "conflict" or "collision" in actual communication. This phenomenon will directly lead to obstacles in intercultural communication between China and the West, and even serious misunderstandings between the two sides. To avoid such cross-cultural communication barriers, it is necessary to understand and analyze the causes of such "conflict, collision" and overcome the cultural differences between China and the West, thus improving the ability of intercultural communication. Teaching cultural knowledge in the cultivation of speculative ability is an important way to improve students' cross-cultural thinking ability. Teachers in the public English classroom focus on cultivating students' cross-cultural thinking ability, focusing on the transfer of cultural knowledge, and using a variety of ways to cultivate students' cross-cultural thinking ability is extremely necessary[2]. College English thinking ability mode is shown below.

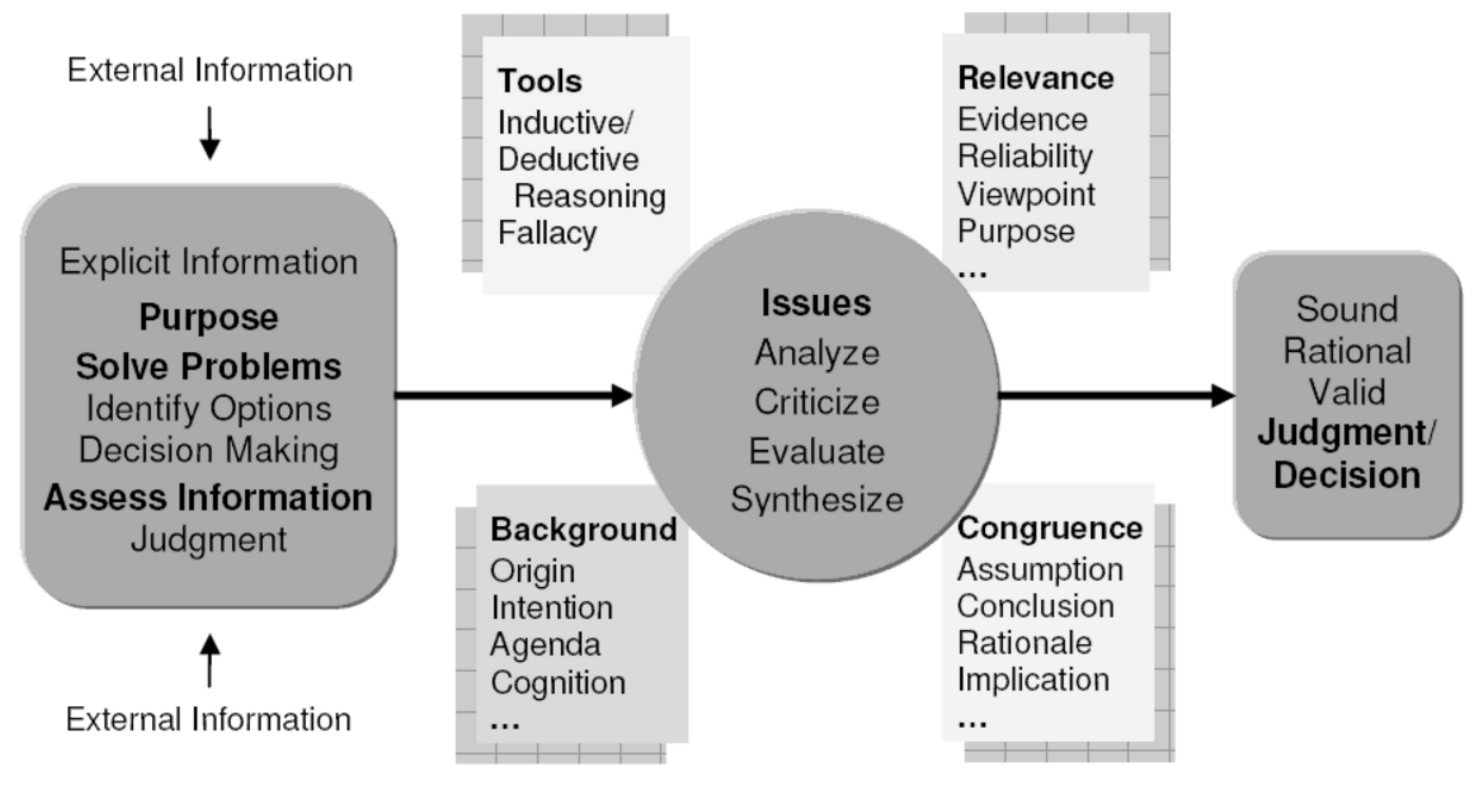

Fig.1 College English thinking ability mode

\section{Under the "Intermet +" situation, the ability of cultivating middle school students' cross-cultural thinking ability}

With the acceleration of the integration of the Internet and traditional industries, "Internet + education" has become an irreversible trend. Under the "Internet + " situation, there are some new ways to cultivate the intercultural thinking ability of middle school students. 


\subsection{Using the "Network Teaching Platform" to Train Students' Intercultural Thinking Ability}

Under the Internet situation, the "network teaching platform" has developed rapidly. At present, well-known network teaching platforms such as Wisdom Tree and Fan Ya have appeared in China. These teaching platforms are jointly developing "online courses" with many universities. It is a good way to cultivate cross-cultural thinking skills with the help of "network courses". At present, our school (Qingdao Vocational and Technical College) has cooperated with the wisdom tree teaching platform to develop the online course of "Western Culture", and set this course as "Network Public Elective Course" for the students to elect. This "Network Public Elective Course" is attended by all the teachers of the Public English Teaching and Research Section. The course team separates the knowledge points of all Western cultures involved in the public English textbooks, and then assigns the knowledge modules of these Western cultures to different teachers according to their respective cultural preferences and cultural accumulation. Each teacher is responsible for a cultural knowledge module, making micro-classes of Western cultural thematic modules, and finally putting all the micro-courses on the online teaching platform, and then has the "Western Culture" "Internet Public Elective Course". Each semester, students can take this course through a "network elective course". Students conduct micro-courses to watch and complete related courses through the network. The use of this "network public elective course" to carry out cultural teaching completely breaks the time, space, teaching teachers and the number of lecturers, which is a useful and necessary supplement to the offline public English classroom teaching. The "Western Culture" Network Public Elective Course provides a systematic study and guidance material for students' cultural learning, and it is a major change in the way of the intercultural discernment ability of our students under the "Internet +" situation. In addition, some teachers in our school also make full use of the way of flipping classrooms to cultivate cross-cultural thinking ability, which is also loved and recognized by students[3]. College English speculative cognition model as shown below.

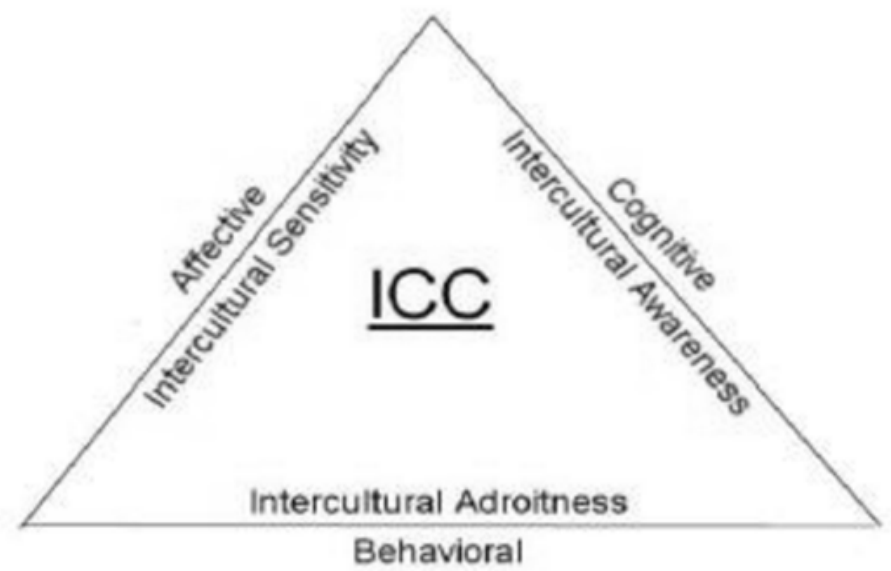

Fig.2 College English speculative cognition model

\subsection{Guide students to individualized cultural learning with the help of the Internet}

The emergence of the Internet has greatly changed the learning model, making non-teacher learning possible. For learners, they can use the Internet to learn the cultural topics of their interest based on their personal interests. They do not need to be completely attached to the teacher's explanation of a cultural theme. In our hospital (Qingdao Vocational and Technical College), in terms of cross-cultural thinking ability training, teachers adopt a student-oriented approach, teachers as counseling, and a network-led approach. The main role of teachers in the cultivation of 
cross-cultural thinking ability is the leader. The specific method is: the teacher first lists the cultural themes involved in the textbook according to the syllabus requirements, and then divides the students into small groups, usually $4 \sim$ A group of 6 people is appropriate. Each group selects one or two topics from the listed cultural topics according to their interests. Each group needs to complete the in-depth study through the Internet within a specified time (usually 10 weeks), and then form a study. report. After the student group has completed its own study, usually at the end of the semester, the teacher allows each group to present their learning outcomes in the classroom. The methods can be diversified, such as through PPT or simulated performances. After the group is displayed, the teacher will supplement or emphasize the appropriate knowledge according to the group's knowledge display. Before the group presentation, teachers can set up some reward items themselves, and after the group of students is displayed, they will give appropriate rewards to individual students or groups. This kind of student-centered cultural learning method can not only mobilize the enthusiasm of students, but also avoid the tiredness caused by students' interest problems. At the same time, the classroom culture theme display of students is also a kind of learning for teachers[4].

\subsection{Teaching of cultural fragmentation with the help of mobile internet}

With the wave of mutual "networking +", the use of mobile Internet has gradually occupied a dominant position among students and teachers. While enjoying the convenience of mobile Internet life, teachers and students also enrich the teaching methods of teachers and the way students learn. Many teachers now complain that students in the classroom don't like to listen, and they like to look at their phones. Students are either immersed in the news client, either in the blog, in WeChat or QQ, in an app, in a post, or in a beauty sing, or not immersed in a classroom teacher. In the lecture. In the age of the Internet, teachers do not have to complain that students do not love learning. They are immersed in the Internet, which is actually a kind of learning[5]. Why don't we take advantage of the characteristics of students who like mobile networks and move some classroom teaching to the mobile network? The Public English Teaching and Research Section of our institute (Qingdao Vocational and Technical College) made full use of the characteristics that students like to browse the mobile network and opened the English learning WeChat public number. Every student is concerned about this WeChat public number. The Public English Teaching and Research Section will collect some stories related to Western culture from teachers and students. Pick out stories that are both interesting and informative, and regularly send them to students in the hospital through the English learning WeChat public account. Students and teachers can use the piecemeal time before, after, and after the car to read these little stories. They learn the culture while killing time. This method has generally been recognized and praised by teachers and students. In this way, teachers and students are both providers of cultural materials and learners of cultural content.

\section{Summary}

These new ways of cultivating cross-cultural thinking ability under the "Internet + " situation have placed new demands on students, teachers and schools: for teachers, in order to adapt to the teaching reform under the form of "network +", teachers need to re-examine Teachers' quality requirements to develop effective response measures; for students, the need to improve self-control, self-management and self-monitoring ability to better adapt to the rapidly changing learning model, and in the increasingly diversified teaching methods Benefit from it. For schools, it is necessary to establish a more complete Internet teaching system. It is necessary to adapt to the development of Internet technology, and appropriately reform the original personnel training methods and teaching models to provide necessary support for teachers and students. 


\section{Acknowledgements}

Fund project: Shandong province social science planning research project, foreign language and literature research special subject. Cultivating Model Establishment of cross-cultural critical ability in college English teaching under the concept of "Internet +" .Project number: 18CWZJ03

\section{References}

[1] Fangpeng GAI. Application of Multimodal Discourse Analysis in Intercultural Communication Teaching [J]. Cross-Cultural Communication, 2013, 9(2).

[2] Juan WU. A Content Analysis of the Cultural Content in the EFL Textbooks [J]. Canadian Social Science, 2010, 6(5).

[3] Yunlong HUANG. Constructing Intercultural Communicative Competence Framework for English Learners [J]. Cross-Cultural Communication, 2014, 10(1).

[4] Chunyan CHENG. Exploration \&amp; Analysis of Intercultural Communication Ability Cultivation in College English Teaching [J]. Cross-Cultural Communication, 2014, 10(3).

[5] Honglin Zhu. College English Teaching Viewed from the Perspective of Intercultural Communication [J]. English Language Teaching, 2010, 3(3). 